\title{
Newly Proposed ALBI Grade and ALBI-T Score as Tools for Assessment of Hepatic Function and Prognosis in Hepatocellular Carcinoma Patients
}

\author{
Atsushi Hiraoka ${ }^{a}$ Takashi Kumada $^{b}$ Kojiro Michitaka ${ }^{a}$ Masatoshi Kudo ${ }^{c}$ \\ ${ }^{a}$ Gastroenterology Center, Ehime Prefectural Central Hospital, Matsuyama, Japan; \\ ${ }^{b}$ Department of Gastroenterology and Hepatology, Ogaki Municipal Hospital, Gifu, Japan; \\ cDepartment of Gastroenterology and Hepatology, Kinki University School of Medicine, \\ Osaka, Japan
}

\author{
Keywords \\ Hepatocellular carcinoma $\cdot$ Albumin-bilirubin grade $\cdot$ ALBI-T score $\cdot$ Child-Pugh \\ classification · Prognosis · Modified ALBI grade
}

\begin{abstract}
Background: Because of the rapid progression of antiviral treatment options and the increasing frequency of nonviral-related hepatocellular carcinoma $(\mathrm{HCC})$ due to the aging of society, the number of HCC patients with good hepatic function has been increasing and a more detailed method of assessment of hepatic function is needed. The Child-Pugh classification (CP) is used worldwide as an assessment tool for hepatic reserve function, even though it has some weaknesses. Recently, the albumin-bilirubin (ALBI) grade, calculated based on only albumin and total bilirubin, was proposed, and recent investigations have suggested that ALBI grade instead of CP can be used as an assessment tool for hepatic function as part of therapeutic strategies such as Barcelona Clinic Liver Cancer staging and a practical guideline presented by the Japan Society of Hepatology as well for total staging scoring systems. There has been an increasing number of reports showing that it has better capability than CP for HCC patients who undergo not only curative but also palliative treatments. Transcatheter arterial chemoembolization (TACE) is a major palliative treatment used for unresectable HCC, and the idea of TACE-refractory status has been proposed to indicate the possibility of switching to a tyrosine kinase inhibitor (TKI). However, TKI administration requires a maintained hepatic reserve function, thus the importance of assessment of hepatic function in patients undergoing TACE treatments has increased. We consider that ALBI grade might also play a significant role as part of a detailed assessment of relative changes in hepatic function during treatment. In
\end{abstract}




\section{Liver Cancer}

\begin{tabular}{l|l}
\hline Liver Cancer 2019;8:312-325 \\
\hline DOI: 10.1159/000494844 & $\begin{array}{l}\text { () 2018 S. Karger AG, Basel } \\
\text { www.karger.com/lic }\end{array}$ \\
\hline
\end{tabular}

Hiraoka et al.: ALBI Grade in HCC

this review, we evaluate the practical usefulness of ALBI grade for assessing hepatic function and HCC prognosis. Key Message: A detailed assessment of hepatic function is required for recent HCC therapeutic strategies. ALBI grade may be a powerful tool to improve treatment options for affected patients.

(C) 2018 S. Karger AG, Basel

\section{Introduction}

Liver cancer, which is nearly always hepatocellular carcinoma (HCC), has been reported to be the sixth-most common cancer and third-most common cause of cancer death worldwide [1]. It is well known that the prognosis of affected patients is dependent on tumor burden and hepatic reserve function [2]. With recent progress in the development of antiviral therapies (e.g., direct-acting antivirals against hepatitis $C$ virus $[3,4]$, nucleoside analogs against hepatitis B virus [5-8]) and the increase in cases of nonviral HCC associated with the aging of society [9], hepatic reserve function in HCC patients has steadily improved [10-14]. In addition, the development of imaging (e.g., contrast-enhanced ultrasonography [15] and gadolinium ethoxybenzyl diethylenetriamine penta-acetic acid-enhanced MRI [EOB-MRI] [16]) and treatment modalities (e.g., radiofrequency ablation [RFA] [17, 18], and the administration of sorafenib [19, 20], regorafenib [21], and lenvatinib [22]) have made it possible to diagnose HCC at an earlier stage, resulting in improved prognosis. On the other hand, though the Child-Pugh classification (CP) [23] has become a standard evaluation tool used for hepatic reserve function worldwide, a more effective method is required according to the recent clinical trend.

The CP has some weaknesses including subjective factors (ascites and encephalopathy) as well as interrelated factors (serum albumin and ascites), and it was not established statistically. On the other hand, a simple and statistical evaluation method for hepatic function, the albumin-bilirubin (ALBI) grade, which is calculated using only serum albumin and total bilirubin $\left[\left(\log _{10}\right.\right.$ bilirubin $($ in $\left.\mu \mathrm{mol} / \mathrm{L}) \times 0.66\right)+($ albumin $($ in $\mathrm{g} / \mathrm{L}) \times-0.085)$ : grades $1,2,3=$ $\leq-2.60,<-2.60$ to $\leq-1.39,>-1.39$, respectively] was recently proposed [24].

Several treatment algorithms and total scoring systems for HCC have been proposed to improve patient outcome, many of which use CP (Table 1). This study was conducted to review the evidence supporting the use of ALBI grade for such algorithms and systems and the treatment of HCC patients.

\section{ALBI Grade for Treatment Algorithms}

Various studies that attempted to use ALBI grade with existing HCC treatment algorithms have been reported (Table 2). Along with the Barcelona Clinic Liver Cancer staging (BCLC) $[25,26]$, used as a treatment algorithm for HCC in western countries, CP is utilized for assessing hepatic reserve function. Chan et al. [27] demonstrated that the overall prognostic performance of ALBI grade-based and CP-based BCLC was similar, as they were highly concordant with a weighted $\kappa$ value of 0.917 , as noted in a multicenter cohort $(n=3,696)$. Pinato et al. [28] reported that the prognostic performance of ALBI grade is particularly appealing for intermediate-stage disease (BCLC-B), in which it is a widely generalizable biomarker able to overcome the survival heterogeneity of BCLC-B cases. Other recent studies have proposed subgrading for BCLC-B, because of its heterogeneous characteristic $[29,30]$. The modified intermediate liver cancer criteria (MICAN), a subgrading for BCLC-B using the ALBI grade, have also been proposed; compared to the other systems examined, they show a good ability 
Table 1. Previously proposed treatment algorithms and total scoring systems for HCC

\begin{tabular}{|c|c|c|c|c|c|}
\hline & Liver factors & HCC factors & Other factors & First author [Ref.] & Year \\
\hline \multicolumn{6}{|l|}{ Treatment algorithm } \\
\hline BCLC & $\begin{array}{l}\mathrm{CP} / \text { portal } \\
\text { hypertension }\end{array}$ & tumor size and number, PVTT & PS & $\begin{array}{l}\text { Llovet [25] } \\
\text { Forner [26] }\end{array}$ & $\begin{array}{l}1999 \\
2018\end{array}$ \\
\hline $\begin{array}{l}\text { Bolondi's BCLC-B } \\
\text { subgrading }\end{array}$ & CP score & up to 7 criteria & PS & Bolondi [29] & 2012 \\
\hline $\begin{array}{l}\text { Kinki criteria for } \\
\text { BCLC-B subgrading }\end{array}$ & CP score & up to 7 criteria & none & Kudo [30] & 2015 \\
\hline $\begin{array}{l}\text { MICAN criteria for } \\
\text { BCLC-B subgrading }\end{array}$ & ALBI & up to 7 criteria & none & Hiraoka [31] & 2016 \\
\hline JSH guidelines & $\mathrm{CP} / \mathrm{LD}$ & $\begin{array}{l}\text { tumor size and number } \\
\text { (intrahepatic venous } \\
\text { invasion and EHM) }\end{array}$ & none & Kokudo [32] & 2015 \\
\hline APASL guidelines & $\mathrm{CP}$ & $\begin{array}{l}\text { tumor size and number, } \\
\text { macrovascular invasion, EHM }\end{array}$ & none & Omata [91] & 2017 \\
\hline HKLC & $\mathrm{CP}$ & $\begin{array}{l}\text { tumor size and number, } \\
\text { intrahepatic venous invasion }\end{array}$ & PS & Yau [92] & 2014 \\
\hline \multicolumn{6}{|l|}{ Total scoring system } \\
\hline Okuda & $\begin{array}{l}\text { albumin, } \\
\text { bilirubin, } \\
\text { ascites }\end{array}$ & $\begin{array}{l}\text { tumor morphology } \\
\text { (uninodular and extension } \leq 50 \% \text {, } \\
\text { multinodular and extension } \\
\leq 50 \% \text {, massive or extension } \\
>50 \% \text { ), PVTT }\end{array}$ & none & Okuda [35] & 1985 \\
\hline CLIP & $\mathrm{CP}$ & $\begin{array}{l}\text { tumor size }(</ \geq 50 \% \text { of liver }) \text {, } \\
\text { PVTT }\end{array}$ & AFP & CLIP [36] & 1998 \\
\hline JIS & $\mathrm{CP}$ & TNM of LCSGJ & none & Kudo [2] & 2003 \\
\hline m-JIS & LD & TNM of LCSGJ & none & $\begin{array}{l}\text { Nanashima [39] } \\
\text { Ikai [40] }\end{array}$ & $\begin{array}{l}2004 \\
2006\end{array}$ \\
\hline bm-JIS & $\mathrm{CP}$ & TNM of LCSGJ & AFP, AFP-L3, DCP & Kitai [38] & 2008 \\
\hline Tokyo & $\begin{array}{l}\text { albumin, } \\
\text { bilirubin }\end{array}$ & tumor size and number & none & Tateishi [37] & 2005 \\
\hline BALAD & $\begin{array}{l}\text { albumin, } \\
\text { bilirubin }\end{array}$ & none & AFP, AFP-L3, DCP & Toyoda $[41,43]$ & $\begin{array}{l}2006 \\
2017\end{array}$ \\
\hline BALAD-2 & $\begin{array}{l}\text { albumin, } \\
\text { bilirubin }\end{array}$ & none & AFP, AFP-L3, DCP & $\begin{array}{l}\text { Berhane [42] } \\
\text { Toyoda [43] }\end{array}$ & $\begin{array}{l}2016 \\
2017\end{array}$ \\
\hline GALAD & none & none & $\begin{array}{l}\text { AFP, AFP-L3, DCP, } \\
\text { age, sex }\end{array}$ & Caviglia [44] & 2016 \\
\hline ALBI-T & ALBI & TNM of LCSGJ & none & Hiraoka [49] & 2016 \\
\hline m-ALBI-T & m-ALBI & TNM of LCSGJ & none & Hiraoka $[14,50]$ & $\begin{array}{l}2018, \\
2017\end{array}$ \\
\hline
\end{tabular}

HCC, hepatocellular carcinoma; BCLC, Barcelona Clinic Liver Cancer staging; PS, ECOG performance status; CP, Child-Pugh classification; PVTT, portal-vein tumor thrombosis; MICAN, modified intermediate stage of liver cancer criteria; JSH, Japan Society of Hepatology; LD, liver damage classification; APASL, Asia-Pacific Association for the Study of the Liver; HKLC, Hong Kong Liver Cancer classification system; CLIP, Cancer of the Liver Italian Program; JIS, Japan Integrated Staging score; EHM, extrahepatic metastasis; LCSGJ, Liver Cancer Study Group of Japan; m-JIS, modified JIS; bm-JIS, biomarker combined JIS; AFP, $\alpha$-fetoprotein; AFP-L3, fucosylated AFP; DCP, des- $\gamma$-carboxy prothrombin; BALAD, bilirubin, albumin, AFP-L3, AFP, and DCP model; ALBI, albumin-bilirubin grade; ALBI-T, ALBI-TNM of LCSGJ score; m-ALBI, modified ALBI grade; m-ALBI-T, mALBI-TNM of LCSGJ score. 


\section{Liver
Cancer}

\begin{tabular}{l|l}
\hline Liver Cancer 2019;8:312-325 \\
\hline DOI: 10.1159/000494844 & $\begin{array}{l}\text { @ 2018 S. Karger AG, Basel } \\
\text { www.karger.com/lic }\end{array}$ \\
\hline
\end{tabular}

Hiraoka et al.: ALBI Grade in HCC

Table 2. Reports comparing ALBI grade and CP using the existing HCC treatment algorithm

\begin{tabular}{|c|c|c|c|c|c|}
\hline & Study area & Patients, $n$ & Outcome & First author [Ref.] & Year \\
\hline BCLC & China & 3,696 & $\begin{array}{l}\text { C index } \\
\text { ALBI vs. CP: } 0.750 \text { vs. } 0.750\end{array}$ & Chan [27] & 2016 \\
\hline BCLC & $\begin{array}{l}\text { International } \\
\text { research }\end{array}$ & 2,426 & $\begin{array}{l}\text { C index } \\
\text { ALBI vs. CP: } 0.68 \text { vs. } 0.56\end{array}$ & Pinato [28] & 2017 \\
\hline $\begin{array}{l}\text { BCLC-B } \\
\text { subgrade }\end{array}$ & Japan & $\begin{array}{l}754 \\
\text { (all patients) } \\
396 \text { (treated } \\
\text { with TACE) }\end{array}$ & $\begin{array}{l}\text { AIC } \\
\text { MICAN [31] vs. Bolondi [29] vs. Kinki } \\
\text { [30]: } 990.5 \text { vs. } 993.0 \text { vs. } 1,001.4 \\
\text { MICAN vs. Bolondi vs. Kinki: } 508.7 \text { vs. } \\
512.0 \text { vs. } 514.1\end{array}$ & Hiraoka [31] & 2016 \\
\hline JSH guideline & Japan & 3,495 & $\begin{array}{l}\text { AIC } \\
\text { ALBI vs. LD vs. CP: } 22,291.8 \text { vs. } \\
22,379.6 \text { vs. } 22,392.1\end{array}$ & Hiraoka [34] & 2017 \\
\hline
\end{tabular}

HCC, hepatocellular carcinoma; ALBI, albumin-bilirubin grade; BCLC, Barcelona Clinic Liver Cancer staging; CP, Child-Pugh classification; MICAN, modified intermediate stage of liver cancer criteria; AIC, Akaike's information criterion; JSH, Japan Society of Hepatology; LD, liver damage classification.

to stratify the prognoses of all BCLC-B patients including those treated with transcatheter arterial chemoembolization (TACE) [31].

On the other hand, the evidence-based clinical practice guideline for HCC developed by the Japan Society of Hepatology (JSH) [32] uses CP and the liver damage classification (LD) based on the rate of indocyanine green retention at 15 min (ICG-R15) [33]. A recent report noted that the assessment ability of hepatic reserve function shown by ALBI grade was adequate for use in the JSH guideline instead of CP and LD [34]. Nevertheless, a prospective validation study to confirm the possibility of ALBI as a tool for assessing hepatic reserve function should be performed.

\section{ALBI Grade for Total Prognostic Scoring System and Prognostic Value with Each Therapeutic Modality}

Various total scoring systems have been proposed to predict the prognosis of HCC and have been found useful for comparing therapeutic results from different institutions as well as therapeutic modalities. The first system introduced to combine tumor burden and hepatic function was the Okuda staging system [35], which had become accepted worldwide. Subsequently, Cancer of the Liver Italian Program score (CLIP) [36], Japan Integrated Staging score (JIS) [2], Tokyo score [37], biomarker JIS (bm-JIS) [38], and modified JIS (m-JIS) with LD [39, 40] were proposed, and include similar factors like tumor burden and hepatic function. On the other hand, some unique systems that do not use tumor or hepatic function factors have also been reported, including BALAD [41], BALAD-2 [42, 43], and GALAD [44] (Table 1). Of these, CLIP is widely used in western countries and the JIS in Japan. HCC is often a smaller tumor when diagnosed in Japan than in other countries, due to the good performance of HCC surveillance. As a result, the tumor node metastasis (TNM) staging presented by the Liver Cancer Study Group of Japan (LCSGJ) [45] is suitable for HCC practice in Japan. The reason 
Table 3. Prognostic scoring systems using ALBI grade

\begin{tabular}{|c|c|c|c|c|c|}
\hline $\begin{array}{l}\text { Original } \\
\text { scoring } \\
\text { system }\end{array}$ & $\begin{array}{l}\text { Study } \\
\text { area }\end{array}$ & Patients, $n$ & Outcome & $\begin{array}{l}\text { First author } \\
\text { [Ref.] }\end{array}$ & Year \\
\hline CLIP & Taiwan & 142 & $\begin{array}{l}\text { AIC } \\
\text { ALBI vs. CP: } 995.0 \text { vs. } 1,001.1\end{array}$ & Shao [47] & 2016 \\
\hline CLIP & China & 1,973 & $\begin{array}{l}\text { AIC } \\
\text { ALBI vs. CP: } 15,493.47 \text { vs. } 15,534.28\end{array}$ & Chan [48] & 2017 \\
\hline JIS & Japan & 2,584 & $\begin{array}{l}\text { OS of ALBI-T superior to that of JIS for } \\
\text { each corresponding score }(\leq 3)\end{array}$ & Hiraoka [49] & 2016 \\
\hline JIS & China & $\begin{array}{l}1,222 \\
\text { (HBV-related HCC) }\end{array}$ & $\begin{array}{l}\text { AIC } \\
\text { ALBI vs. CP: } 9,836.57 \text { vs. } 9,880.23\end{array}$ & Chan [51] & 2016 \\
\hline JIS & Japan & $\begin{array}{l}\text { 46,681 (all patients) } \\
\text { 18,886 (patients } \\
\text { treated curatively) }\end{array}$ & $\begin{array}{l}\text { AIC } \\
\text { ALBI vs. CP vs. m-ALBI: } \\
256,952.4 \text { vs. } 256,356.7 \text { vs. } 256,955.5 \\
\text { ALBI vs. CP vs. m-ALBI: } \\
57,365.5 \text { vs. } 57,416.3 \text { vs. } 57,133.3\end{array}$ & Hiraoka [50] & 2017 \\
\hline
\end{tabular}

CLIP, Cancer of the Liver Italian Program; ALBI, albumin-bilirubin grade; CP, Child-Pugh classification; AIC, Akaike's information criterion; JIS, Japan Integrated Staging score; m-ALBI, modified ALBI grade; HBV, hepatitis B virus; HCC, hepatocellular carcinoma.

for the good acceptance of the JIS (which uses the TNM staging of LCSGJ) by Japanese institutions is because of its stratification ability and prognostic predictive power, which are considered better than for CLIP score and more suitable for Japanese HCC patients [46]. Although the m-JIS, which uses LD, was initially expected to have greater prognostic predictive power, opportunities for its use have been limited when compared to JIS due to a weakness, i.e., the requirement of an ICG injection for obtaining ICG-R15 results. A more detailed evaluation method for patients with good hepatic function is needed, as the frequency of patients with better hepatic reserve function has recently shown an increasing trend in Japan [10-14].

Based on such clinical needs, the ALBI score/grade was developed by an international study group [24]. It has been reported that the concordance index for a modification of CLIP with ALBI grade (ALBI-CLIP) was higher than CLIP alone, so ALBI-CLIP might provide improved prognosis prediction for advanced HCC cases $[47,48]$. On the other hand, an m-JIS with ALBI grade (ALBI-T score) has also been proposed [49]. Analysis of nationwide survey data obtained in Japan showed that median survival time (MST) determined with ALBI-T score was always superior to that obtained with the corresponding scores of JIS and m-JIS, while Akaike's information criterion (AIC) for ALBI-T score was superior to JIS and m-JIS with LD, especially in early stage HCC cases treated in a curative manner $(41,054.6,41,107.9$, and $41,094.1$, respectively) [50]. Chan et al. [51] also reported the results of a validation study of ALBI-T score for patients infected with hepatitis B virus (Table 3). It is considered that ALBI grade may have a good performance for assessing hepatic reserve function when used in total staging scoring systems. 


\section{Liver
Cancer}

\begin{tabular}{l|l}
\hline Liver Cancer 2019;8:312-325 \\
\hline DOI: 10.1159/000494844 & $\begin{array}{l}\text { @ 2018 S. Karger AG, Basel } \\
\text { www.karger.com/lic }\end{array}$ \\
\hline
\end{tabular}

Hiraoka et al.: ALBI Grade in HCC

Table 4. Prognostic predictive power of ALBI grade compared with others for overall survival

\begin{tabular}{|c|c|c|c|c|c|}
\hline $\begin{array}{l}\text { Therapeutic } \\
\text { modality }\end{array}$ & Study area & Patients & Outcome & $\begin{array}{l}\text { First author } \\
\text { [Ref.] }\end{array}$ & Year \\
\hline Resection & China & 1,242 & $\begin{array}{l}\text { 3-year survival rate } \\
\text { CP-A vs. CP-B: } 63.0 \text { vs. } 53.0 \%(p=0.055) \text {; ALBI } 1 \text { vs. } \\
\text { ALBI 2: } 68.0 \text { vs. } 52.5 \%(p<0.001)\end{array}$ & Wang [52] & 2016 \\
\hline Resection & Taiwan & 491 & $\begin{array}{l}\text { MST } \\
\text { ALBI } 1 \text { vs. ALBI } 2: 62 \text { vs. } 37 \text { months }(p=0.001) \text {; CP } \\
\text { score } 5 \text { vs. CP score } 6: 57 \text { vs. } 36 \text { months }(p=0.235) \\
\text { AIC } \\
\text { ALBI vs. CP: } 4,768.84 \text { vs. } 4,778.16\end{array}$ & $\mathrm{Li}$ [53] & 2017 \\
\hline Resection & China & 318 & $\begin{array}{l}\text { AUC for predicting } \mathbf{0 S} \\
\text { ALBI vs. CP: } 0.650 \text { vs. } 0.511(p=0.009)\end{array}$ & Мa [54] & 2016 \\
\hline RFA & Korea & 368 & $\begin{array}{l}\text { HR of multivariate analysis for OS } \\
\text { ALBI 2: } 2.32(95 \% \text { CI } 1.35-3.99, p=0.002) \text {; CP-B: } \\
1.14(95 \% \text { CI } 0.63-2.06, p=0.66)\end{array}$ & Oh [58] & 2017 \\
\hline TACE & $\begin{array}{l}\text { International } \\
\text { team }\end{array}$ & 3,030 & $\begin{array}{l}\text { C-index and AIC } \\
\text { ALBI vs. CP: } 0.5661 \text { vs. } 0.5586 \text { and } \\
26,963.33 \text { vs. } 26,548.21 \text {, respectively }\end{array}$ & Waked [63] & 2017 \\
\hline TACE & Taiwan & 881 & $\begin{array}{l}\text { AIC } \\
\text { ALBI vs. CP: } 8,094.296 \text { vs. } 8,111.090\end{array}$ & Нo [64] & 2017 \\
\hline Sorafenib & Japan & $\begin{array}{l}282 \\
(\mathrm{CP} \text { score } 5) \\
77 \\
\text { (BCLC-B) }\end{array}$ & $\begin{array}{l}\text { MST } \\
\text { ALBI } 1 \text { vs. ALBI } 2: 17.5 \text { vs. } 9.9 \text { months } \\
(p=0.010) \\
\text { ALBI } 1 \text { vs. ALBI } 2: 17.5 \text { vs. } 10.0 \text { months } \\
(p=0.039)\end{array}$ & Hiraoka [65] & 2017 \\
\hline
\end{tabular}

ALBI, albumin-bilirubin grade; CP, Child-Pugh classification; MST, median survival time; AIC, Akaike's information criterion; AUC, area under the curve; OS, overall survival; RFA, radiofrequency ablation; HR, hazard ratio; CI, confidence interval; TACE, transcatheter arterial chemoembolization; BCLC-B, Barcelona Clinic Liver Cancer stage B.

\section{Prognosis Prediction Ability of ALBI Grade in Curative and Palliative Treatment}

\section{Curative Treatment}

ALBI grade predicts overall survival (OS) more accurately than CP in patients with HCC who undergo hepatic resection [52-54]. Moreover, some studies have reported that it had a better performance than CP, the model for end-stage liver disease (MELD) score, and the ICG-R15 for the prediction of posthepatectomy liver failure [52, 55-57]. Similarly, the prognostic predictive value of ALBI grade has been reported as being better than CP in cases that receive RFA [58]. Other studies have proposed the development of a nomogram based on ALBI grade and other clinical data for predicting the 2- and 5-year survival of patients with recurrence after a hepatectomy [59] as well as assess the long-term outcomes of RFA for early-stage HCC [60].

\section{Palliative Treatment}

In patients who receive palliative treatment, such as transarterial locoregional therapy (transcatheter arterial chemoembolization [TACE] or radioembolization), ALBI grade has 
also shown a good prognostic predictive ability $[61,62]$ and been used to categorize patients receiving TACE for BCLC-B HCC [63]. Furthermore, Ho et al. [64] reported that ALBI grade showed a higher level of homogeneity and the lowest AIC value when compared to CP and MELD in patients who underwent TACE. In sorafenib-treated HCC patients, it was shown to be a better tool than $\mathrm{CP}$ for assessing hepatic function [65]. In fact, with each type of treatment, ALBI grade has been shown to be superior for the assessment of hepatic function (Table 4).

\section{ALBI Grade for Treatment Selection in Curative Treatment}

A few studies have investigated whether ALBI grade can be used for patient selection for available treatment modalities. Chong et al. [66] compared hepatic resection and RFA after propensity score-matching in BCLC-0/A HCC patients with an ALBI grade of 1 and reported that hepatic resection showed superior OS and disease-free survival of patients who underwent RFA ( $p<0.001$, respectively). In another study that compared hepatic resection with microwave ablation (MWA), patients with ALBI grade 1 who underwent the former had better overall and disease-free survival rates, while the latter resulted in significantly better OS in those with ALBI $\geq$ grade 2 [67].

Based on these findings, it is considered that ALBI grade might be able to identify patients with better hepatic function who would obtain a survival benefit by undergoing resection as well as those who would not benefit due to worse hepatic function. In a retrospective analysis of the indicators of RFA for HCC ( $<3 \mathrm{~cm}$ and $\leq 3$ tumors), there was only a slight therapeutic efficacy for improving prognosis following RFA in ALBI grade 3 cases [68]. Furthermore, Ogasawara et al. [69] noted that sorafenib may be indicated for all patients with unresectable HCC and classified ALBI grade 1, and for some with ALBI grade 2. On the other hand, King et al. [70] reported that patients with ALBI $\geq$ grade 2 or CP-B seemed to derive limited therapeutic benefit from sorafenib treatment. Thus, ALBI grade may play a considerable role in determining treatment modality in current HCC practice, when considering the risks and benefits of the various treatments available.

\section{ALBI Grade for the Assessment of Hepatic Reserve Function in the Era of Multiple Tyrosine Kinase Inhibitors}

TACE is performed worldwide as a standard therapy for BCLC-B HCC [26, 71]. Recently, tyrosine kinase inhibitors (TKIs) were developed [19, 21, 22, 72], and the criteria for determining TACE-refractory status used to judge the efficacy of switching to a TKI $[73,74]$ hypothesized that it would prolong the prognosis of unresectable HCC patients, but the maintenance of hepatic reserve function is also important for the safe use of TKIs. Although some prognostic prediction methods for patients treated with TACE have been presented [75-80], no study has examined TACE-refractory strategies from the view of a relative decline in hepatic reserve function during repeated TACE. A recent report noted that a negative relative change in hepatic reserve function during repeated TACE procedures for BCLC-B HCC was more easily detected with ALBI grade than with CP [65]. Of course, adequate determination of TACE-refractory status is recognized as important for improving the prognosis of patients with unresectable HCC.

Although the TACE-refractory criteria items used in Japan include imaging findings and tumor markers, most clinicians $(>80 \%)$ judge TACE-refractory patients based on response shown by imaging findings, while only a small percentage $(10.3 \%)$ use tumor marker findings as a reference [73]. The clinical items included in the Japanese criteria for TACE-refractory 


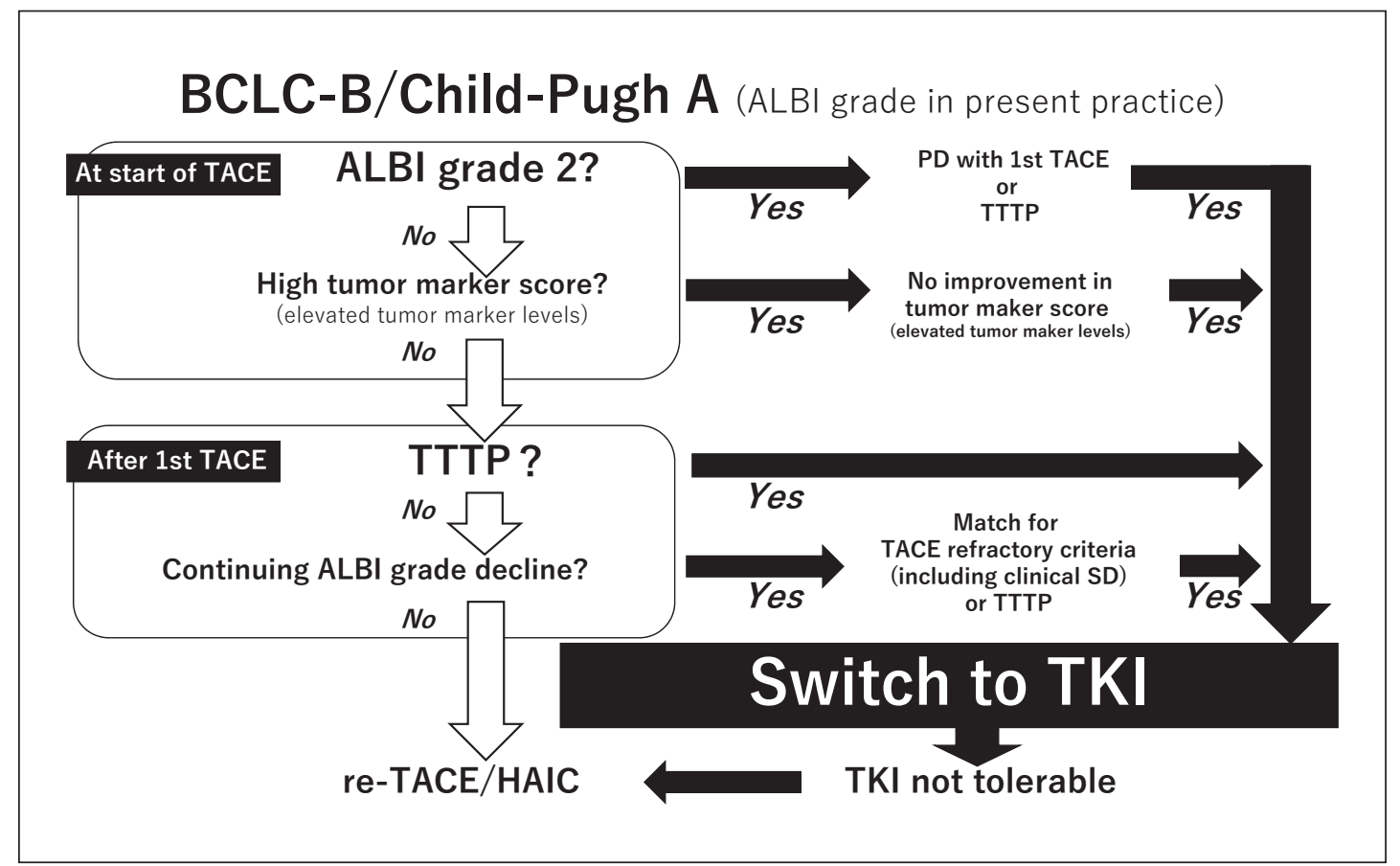

Fig. 1. TACE-refractory with ALBI grade, tumor markers, and imaging findings algorithm. Possibility of complementary therapeutic strategy using ALBI grade so as to not lose the chance for switching to a TKI in BCLCB HCC patients treated with TACE. ALBI, albumin-bilirubin; TKI, tyrosine-kinase inhibitor; BCLC-B, intermediate stage of Barcelona Clinic Liver Cancer; TACE, transcatheter arterial chemoembolization; TTTP, time to TACE progression; HAIC, hepatic arterial infusion chemotherapy; SD, stable disease; PD, progressive disease.

status have ambiguities, including some with no cut-off value of tumor markers. In examinations prior to treatment and after starting TACE, tumor marker score derived from marker levels has been reported to be predictive of a poor response and prognosis in BCLC-B patients with CP-A undergoing treatment with TACE (positive for each of $\alpha$-fetoprotein [AFP] $\geq 100$ $\mathrm{ng} / \mathrm{mL}$, fucosylated AFP [AFP-L3] $\geq 10 \%$, and des- $\gamma$-carboxy prothrombin [DCP] $\geq 100 \mathrm{mAU} /$ $\mathrm{mL}=\mathrm{a}$ "tumor marker score" of 1 point; the response to TACE is expected to be very poor in patients with $\geq 2$ points) $[78,81]$.

After starting TACE, even a slight enlargement noted from imaging findings (contrastenhanced computed tomography [CECT] or EOB-MRI) is indicative of a risk of a rapid decline in OS (sum of maximum diameters of each viable area of the 5 largest tumors on follow-up imaging after the 1st TACE as baseline is compared to imaging findings [CECT or EOB-MRI] obtained after each TACE; a ratio $>1.2$ is considered as "time to TACE progression [TTTP]") $[79,80]$. Indeed, we have often encountered cases in which therapeutic response noted from imaging findings is recognized as stable disease (SD), in spite of no decline in tumor marker levels, and rapid progression as a result of additional TACE procedures has been observed [78]. An additional procedure after attaining a TACE-refractory status is not only less effective for preventing tumor progression but also has a harmful influence on hepatic reserve function.

Although CP-A status is an indispensable condition with TKI treatment, the hazard ratio (HR) for ALBI grade 2 is higher than grade 1, with regard to OS, in CP-A patients treated with sorafenib (HR 1.68, 95\% CI 1.43-1.97, $p<0.001$ ) [82]. Moreover, for those treated with sorafenib with a CP score of 5 , the prognosis for ALBI grade 1 (among all patients) and BCLC-B patients was better than for ALBI grade 2 patients (MST: 17.5 vs. 9.9 months and 17.5 vs. 10.0 


\section{Liver

months, respectively; $p=0.01$ and $p=0.039$, respectively) [65]. Kuo et al. [83] reported that patients with ALBI grade 1 at the start of sorafenib treatment had a better prognosis than those with ALBI grade 2 (MST 8.5 vs. 4.4 months, $p=0.003$ ). ALBI grade 2 at the start of sorafenib therapy and a worsening ALBI grade during treatment were strong prognostic factors for mortality $(p<0.001)$. In this era of multiple TKI options, second-line treatment is available when sorafenib treatment fails, and the importance of a detailed assessment of hepatic reserve function has grown. Indeed, ALBI grade has been reported to play a significant prognostic role in OS after sorafenib therapy in patients eligible for second-line therapy (MST for ALBI grades 1, 2, and 3: 17.5, 7.5, and 1.9 months, respectively; $p<0.001$ ) [84].

In addition to evaluating imaging findings $[79,80]$ and tumor marker levels [78], a detailed assessment of a negative change in hepatic reserve function while undergoing TACE procedures is also important for judging TACE-refractory status adequately, so as to not miss the opportunity to switch to a TKI and gain its possible therapeutic efficacy (Fig. 1). Recently, Lee et al. [85] proposed ALBI progressive disease (PD) criteria for BCLC-C patients treated with sorafenib by using 3 factors to consider a second-line trial or salvage therapy (ALBI grade 3 at PD, a new extrahepatic lesion, and early PD within 4 months). It is important for attending physicians to keep in mind the importance of maintaining hepatic reserve function during TACE for unresectable HCC in order to widen the possibility of additional therapeutic options.

\section{Weaknesses and Potential of ALBI Grades and Perspectives for the Near Future}

A weakness of ALBI grades may be that involving the prognostic predictive power of decompensated cirrhosis status. A comparison between ALBI grade and MELD performed by Khabbaz et al. [86] in patients undergoing creation of a transjugular intrahepatic portosystemic shunt due to portal hypertension complications (variceal bleeding, 55\%; ascites, 35\%; other, $10 \%$ ), only MELD was associated with transplant-free survival, while Ronald et al. [87] reported that MELD was a better predictor than ALBI grade of both 30-day mortality and OS (C-index: 0.74 vs. 0.64 and 0.63 vs. 0.59 , respectively) .

On the other hand, Lo et al. [88] reported the utility of the complementary use of CP and ALBI scores to predict the risk of liver toxicity after stereotactic ablative radiation therapy against HCC (2.4\% for CP-A/ALBI score $<-2.76$ and $15.1 \%$ for CP-A/ALBI score $\geq-2.76$ ). Moreover, compared to CP following HCC treatment, an advantage of ALBI grade is that it is calculated by using a continuous variable (ALBI score). For example, an ALBI grade of 2 has a very wide range, similar to $\mathrm{CP}-\mathrm{B}$ and should be divided into subgrades for more detailed assessment of hepatic reserve function.

Since ALBI score has a good correlation with ICG-R15 ( $r=0.563 ; 95 \%$ CI $0.550-0.570$; $p<0.0001$ ), it could be modified to 4 grades, m-ALBI $1,2 \mathrm{a}, 2 \mathrm{~b}$, and 3 , using ICG-R15 results as $30 \%$ (cut-off value for ALBI score $=-2.270$, AUC $0.828,95 \%$ CI $0.823-0.833$ ), as noted in a previous study [50]. The results of that study also showed that for each TNM stage of LCSGJ, the prognosis according to $\mathrm{m}$-ALBI grade was well stratified ( $p<0.001$, respectively). As a result, it was found that $\mathrm{m}$-ALBI-T score using $\mathrm{m}$-ALBI grade and TNM had a better prognostic predictive ability for early-stage HCC patients who underwent curative treatment. A recent validation analysis of m-ALBI-T also showed that it had better prognostic predictive value than ALBI-T and JIS [14]. In addition, Na et al. [89] reported that ALBI grade showed better discriminative performance than $\mathrm{CP}$ in patients receiving curative treatment ( $\mathrm{C}$ index: 0.667 vs. 0.624), and Dong et al. [90] showed that preoperative ALBI score was significantly related to the OS of solitary HCC patients according to the Milan criteria and CP-A status. Therefore, ALBI/m-ALBI grade may provide a more accurate assessment than CP of HCC patients, especially those treated with a curative intent. 


\section{Liver Cancer}

\begin{tabular}{l|l}
\hline Liver Cancer 2019;8:312-325 \\
\hline DOI: 10.1159/000494844 & $\begin{array}{l}\text { (c) 2018 S. Karger AG, Basel } \\
\text { www.karger.com/lic }\end{array}$ \\
\hline
\end{tabular}

Hiraoka et al.: ALBI Grade in HCC

\section{Conclusion}

There is no doubt that ALBI grade can play an important complementary role in cases of both curative and palliative treatment. Moreover, it is expected that suitable therapeutic strategies can be supplied by determining ALBI/m-ALBI grade, which comply with recent trends of care of HCC patients, especially those scheduled to undergo curative treatment. Although additional prospective analyses are needed, the newly proposed ALBI grade and ALBI-T, including m-ALBI grade and m-ALBI-T, might become powerful tools for improving the prognosis of HCC patients.

\section{Disclosure Statement}

There are no financial disclosures, grants from any organizations, conflicts of interest, and/or acknowledgements for the authors to disclose.

\section{Author Contributions}

A. Hiraoka drafted and wrote the manuscript. T. Kumada and M. Kudo reviewed and approved the final version.

\section{References}

1 Parkin DM, Bray F, Ferlay J, Pisani P. Global cancer statistics, 2002. CA Cancer J Clin. 2005 Mar-Apr;55(2): 74-108.

2 Kudo M, Chung H, Osaki Y. Prognostic staging system for hepatocellular carcinoma (CLIP score): its value and limitations, and a proposal for a new staging system, the Japan Integrated Staging Score (JIS score). J Gastroenterol. 2003;38(3):207-15.

3 Toyoda H, Kumada T, Tada T, Shimada N, Takaguchi K, Senoh T, et al. Efficacy and tolerability of an IFN-free regimen with DCV/ASV for elderly patients infected with HCV genotype 1B. J Hepatol. 2017 Mar;66(3):521-7.

4 Omata M, Nishiguchi S, Ueno Y, Mochizuki H, Izumi N, Ikeda F, et al. Sofosbuvir plus ribavirin in Japanese patients with chronic genotype 2 HCV infection: an open-label, phase 3 trial. J Viral Hepat. 2014 Nov;21(11): 762-8.

5 Dienstag JL, Goldin RD, Heathcote EJ, Hann HW, Woessner M, Stephenson SL, et al. Histological outcome during long-term lamivudine therapy. Gastroenterology. 2003 Jan;124(1):105-17.

6 Hiraoka A, Michitaka K, Kumagi T, Kurose K, Uehara T, Hirooka M, et al. Efficacy of lamivudine therapy for decompensated liver cirrhosis due to hepatitis B virus with or without hepatocellular carcinoma. Oncol Rep. 2005 Jun;13(6):1159-63.

7 Hadziyannis SJ, Tassopoulos NC, Heathcote EJ, Chang TT, Kitis G, Rizzetto M, et al.; Adefovir Dipivoxil 438 Study Group. Long-term therapy with adefovir dipivoxil for HBeAg-negative chronic hepatitis B for up to 5 years. Gastroenterology. 2006 Dec;131(6):1743-51.

8 Chang TT, Liaw YF, Wu SS, Schiff E, Han KH, Lai CL, et al. Long-term entecavir therapy results in the reversal of fibrosis/cirrhosis and continued histological improvement in patients with chronic hepatitis B. Hepatology. 2010 Sep;52(3):886-93.

9 Hiraoka A, Ochi M, Matsuda R, Aibiki T, Okudaira T, Kawamura T, et al. Ultrasonography screening for hepatocellular carcinoma in Japanese patients with diabetes mellitus. J Diabetes. 2016 Sep;8(5):640-6.

10 Ikai I, Arii S, Ichida T, Okita K, Omata M, Kojiro M, et al. Report of the 16th follow-up survey of primary liver cancer. Hepatol Res. 2005 Jul;32(3):163-72.

11 Ikai I, Arii S, Okazaki M, Okita K, Omata M, Kojiro M, et al. Report of the 17th Nationwide Follow-up Survey of Primary Liver Cancer in Japan. Hepatol Res. 2007 Sep;37(9):676-91.

12 Ikai I, Kudo M, Arii S, Omata M, Kojiro M, Sakamoto M, et al. Report of the 18th follow-up survey of primary liver cancer in Japan. Hepatol Res. 2010;40(11):1043-59.

13 Kudo M, Izumi N, Ichida T, Ku Y, Kokudo N, Sakamoto M, et al. Report of the 19th follow-up survey of primary liver cancer in Japan. Hepatol Res. 2016 Mar;46(5):372-90.

14 Hiraoka A, Kumada T, Tsuji K, Takaguchi K, Itobayashi E, Kariyama K, et al. Validation of modified ALBI grade for more detailed assessing hepatic function of hepatocellular carcinoma - multicenter analysis. Liver Cancer. 2018. DOI: $10.1159 / 000488778$. 
15 Hiraoka A, Ichiryu M, Tazuya N, Ochi H, Tanabe A, Nakahara H, et al. Clinical translation in the treatment of hepatocellular carcinoma following the introduction of contrast-enhanced ultrasonography with Sonazoid. Oncol Lett. 2010 Jan;1(1):57-61.

16 Sano K, Ichikawa T, Motosugi U, Sou H, Muhi AM, Matsuda M, et al. Imaging study of early hepatocellular carcinoma: usefulness of gadoxetic acid-enhanced MR imaging. Radiology. 2011 Dec;261(3):834-44.

17 Shiina S, Tateishi R, Arano T, Uchino K, Enooku K, Nakagawa H, et al. Radiofrequency ablation for hepatocellular carcinoma: 10-year outcome and prognostic factors. Am J Gastroenterol. 2012 Apr;107(4):569-77.

18 Hiraoka A, Michitaka K, Horiike N, Hidaka S, Uehara T, Ichikawa S, et al. Radiofrequency ablation therapy for hepatocellular carcinoma in elderly patients. J Gastroenterol Hepatol. 2010 Feb;25(2):403-7.

19 Llovet JM, Ricci S, Mazzaferro V, Hilgard P, Gane E, Blanc JF, et al.; SHARP Investigators Study Group. Sorafenib in advanced hepatocellular carcinoma. N Engl J Med. 2008 Jul;359(4):378-90.

20 Cheng AL, Kang YK, Chen Z, Tsao CJ, Qin S, Kim JS, et al. Efficacy and safety of sorafenib in patients in the AsiaPacific region with advanced hepatocellular carcinoma: a phase III randomised, double-blind, placebocontrolled trial. Lancet Oncol. 2009 Jan;10(1):25-34.

21 Bruix J, Qin S, Merle P, Granito A, Huang YH, Bodoky G, et al.; RESORCE Investigators. Regorafenib for patients with hepatocellular carcinoma who progressed on sorafenib treatment (RESORCE): a randomised, doubleblind, placebo-controlled, phase 3 trial. Lancet. 2017 Jan;389(10064):56-66.

22 Kudo M, Finn RS, Qin S, Han KH, Ikeda K, Piscaglia F, et al. Lenvatinib versus sorafenib in first-line treatment of patients with unresectable hepatocellular carcinoma: a randomised phase 3 non-inferiority trial. Lancet. 2018 Mar;391(10126):1163-73.

23 Pugh RN, Murray-Lyon IM, Dawson JL, Pietroni MC, Williams R. Transection of the oesophagus for bleeding oesophageal varices. Br J Surg. 1973 Aug;60(8):646-9.

24 Johnson PJ, Berhane S, Kagebayashi C, Satomura S, Teng M, Reeves HL, et al. Assessment of liver function in patients with hepatocellular carcinoma: a new evidence-based approach-the ALBI grade. J Clin Oncol. 2015 Feb;33(6):550-8.

25 Llovet JM, Brú C, Bruix J. Prognosis of hepatocellular carcinoma: the BCLC staging classification. Semin Liver Dis. 1999;19(3):329-38.

26 Forner A, Reig M, Bruix J. Hepatocellular carcinoma. Lancet. 2018 Mar;391(10127):1301-14.

27 Chan AW, Kumada T, Toyoda H, Tada T, Chong CC, Mo FK, et al. Integration of albumin-bilirubin (ALBI) score into Barcelona Clinic Liver Cancer (BCLC) system for hepatocellular carcinoma. J Gastroenterol Hepatol. 2016 Jul;31(7):1300-6.

28 Pinato DJ, Sharma R, Allara E, Yen C, Arizumi T, Kubota K, et al. The ALBI grade provides objective hepatic reserve estimation across each BCLC stage of hepatocellular carcinoma. J Hepatol. 2017 Feb;66(2):338-46.

29 Bolondi L, Burroughs A, Dufour JF, Galle PR, Mazzaferro V, Piscaglia F, et al. Heterogeneity of patients with intermediate (BCLC B) Hepatocellular Carcinoma: proposal for a subclassification to facilitate treatment decisions. Semin Liver Dis. 2012 Nov;32(4):348-59.

30 Kudo M, Arizumi T, Ueshima K, Sakurai T, Kitano M, Nishida N. Subclassification of BCLC B Stage Hepatocellular Carcinoma and Treatment Strategies: Proposal of Modified Bolondi's Subclassification (Kinki Criteria). Dig Dis. 2015 0ct;33(6):751-8.

31 Hiraoka A, Kumada T, Nouso K, Tsuji K, Itobayashi E, Hirooka M, et al. Proposed New Sub-Grouping for Intermediate-Stage Hepatocellular Carcinoma Using Albumin-Bilirubin Grade. Oncology. 2016;91(3):153-61.

32 Kokudo N, Hasegawa K, Akahane M, Igaki H, Izumi N, Ichida T, et al. Evidence-based Clinical Practice Guidelines for Hepatocellular Carcinoma: The Japan Society of Hepatology 2013 update (3rd JSH-HCC Guidelines). Hepatol Res. 2015 Jan;45(2):n/a.

33 Omagari K, Ohba K, Kadokawa Y, Hazama H, Masuda J, Kinoshita H, et al. Comparison of the grade evaluated by "Liver damage" of Liver Cancer Study Group of Japan and Child-Pugh classification in patients with hepatocellular carcinoma. Hepatol Res. 2006 Apr;34(4):266-72.

34 Hiraoka A, Kumada T, Kudo M, Hirooka M, Tsuji K, Itobayashi E, et al.; Real-Life Practice Experts for HCC (RELPEC) Study Group and HCC 48 Group (hepatocellular carcinoma experts from 48 clinics). Albumin-Bilirubin (ALBI) Grade as Part of the Evidence-Based Clinical Practice Guideline for HCC of the Japan Society of Hepatology: A Comparison with the Liver Damage and Child-Pugh Classifications. Liver Cancer. 2017 Jun;6(3): 204-15.

35 Okuda K, Ohtsuki T, Obata H, Tomimatsu M, Okazaki N, Hasegawa H, et al. Natural history of hepatocellular carcinoma and prognosis in relation to treatment. Study of 850 patients. Cancer. 1985 Aug;56(4):918-28.

36 The Cancer of the Liver Italian Program (CLIP) Investigators. A new prognostic system for hepatocellular carcinoma: a retrospective study of 435 patients. Hepatology. 1998 Sep;28(3):751-5.

37 Tateishi R, Yoshida H, Shiina S, Imamura H, Hasegawa K, Teratani T, et al. Proposal of a new prognostic model for hepatocellular carcinoma: an analysis of 403 patients. Gut. 2005 Mar;54(3):419-25.

38 Kitai S, Kudo M, Minami Y, Haji S, Osaki Y, Oka H, et al. Validation of a new prognostic staging system for hepatocellular carcinoma: a comparison of the biomarker-combined Japan Integrated Staging Score, the conventional Japan Integrated Staging Score and the BALAD Score. Oncology. 2008;75 Suppl 1:83-90.

39 Nanashima A, Sumida Y, Morino S, Yamaguchi H, Tanaka K, Shibasaki S, et al. The Japanese integrated staging score using liver damage grade for hepatocellular carcinoma in patients after hepatectomy. Eur J Surg Oncol. 2004 Sep;30(7):765-70. 
Hiraoka et al.: ALBI Grade in HCC

40 Ikai I, Takayasu K, Omata M, Okita K, Nakanuma Y, Matsuyama Y, et al.; Liver Cancer Study Group of Japan. A modified Japan Integrated Stage score for prognostic assessment in patients with hepatocellular carcinoma. J Gastroenterol. 2006 Sep;41(9):884-92.

41 Toyoda H, Kumada T, Osaki Y, Oka H, Urano F, Kudo M, et al. Staging hepatocellular carcinoma by a novel scoring system (BALAD score) based on serum markers. Clin Gastroenterol Hepatol. 2006 Dec;4(12):152836.

42 Berhane S, Toyoda H, Tada T, Kumada T, Kagebayashi C, Satomura S, et al. Role of the GALAD and BALAD-2 Serologic Models in Diagnosis of Hepatocellular Carcinoma and Prediction of Survival in Patients. Clin Gastroenterol Hepatol. 2016 Jun;14(6):875-886.e6.

43 Toyoda H, Tada T, Johnson PJ, Izumi N, Kadoya M, Kaneko S, et al.; Liver Cancer Study Group of Japan. Validation of serological models for staging and prognostication of HCC in patients from a Japanese nationwide survey. J Gastroenterol. 2017 Oct;52(10):1112-21.

44 Caviglia GP, Abate ML, Petrini E, Gaia S, Rizzetto M, Smedile A. Highly sensitive alpha-fetoprotein, Lens culinaris agglutinin-reactive fraction of alpha-fetoprotein and des-gamma-carboxyprothrombin for hepatocellular carcinoma detection. Hepatol Res. 2016 Mar;46(3):E130-5.

45 The Liver Cancer Study Group of Japan. The general rules for the clinical and pathological study of primary liver cancer. 6th ed. Tokyo: Kanehara; 2015. p. 26.

46 Kudo M, Chung H, Haji S, Osaki Y, Oka H, Seki T, et al. Validation of a new prognostic staging system for hepatocellular carcinoma: the JIS score compared with the CLIP score. Hepatology. 2004 Dec;40(6):1396-405.

47 Shao YY, Liu TH, Lee YH, Hsu CH, Cheng AL. Modified CLIP with objective liver reserve assessment retains prognosis prediction for patients with advanced hepatocellular carcinoma. J Gastroenterol Hepatol. 2016 Jul; 31(7):1336-41.

48 Chan AW, Chong CC, Mo FK, Wong J, Yeo W, Johnson PJ, et al. Incorporating albumin-bilirubin grade into the cancer of the liver Italian program system for hepatocellular carcinoma. J Gastroenterol Hepatol. 2017 Jan; 32(1):221-8.

49 Hiraoka A, Kumada T, Michitaka K, Toyoda H, Tada T, Ueki H, et al. Usefulness of albumin-bilirubin grade for evaluation of prognosis of 2584 Japanese patients with hepatocellular carcinoma. J Gastroenterol Hepatol. 2016 May;31(5):1031-6.

50 Hiraoka A, Michitaka K, Kumada T, Izumi N, Kadoya M, Kokudo N, et al. Validation and Potential of AlbuminBilirubin Grade and Prognostication in a Nationwide Survey of 46,681 Hepatocellular Carcinoma Patients in Japan: The Need for a More Detailed Evaluation of Hepatic Function. Liver Cancer. 2017 Nov;6(4):325-36.

51 Chan AW, Chong CC, Mo FK, Wong J, Yeo W, Johnson PJ, et al. Applicability of albumin-bilirubin-based Japan integrated staging score in hepatitis B-associated hepatocellular carcinoma. J Gastroenterol Hepatol. 2016 Oct;31(10):1766-72.

52 Wang YY, Zhong JH, Su ZY, Huang JF, Lu SD, Xiang BD, et al. Albumin-bilirubin versus Child-Pugh score as a predictor of outcome after liver resection for hepatocellular carcinoma. Br J Surg. 2016 May;103(6):725-34.

53 Li MX, Zhao H, Bi XY, Li ZY, Huang Z, Han Y, et al. Prognostic value of the albumin-bilirubin grade in patients with hepatocellular carcinoma: validation in a Chinese cohort. Hepatol Res. 2017 Jul;47(8):731-41.

54 Ma XL, Zhou JY, Gao XH, Tian L, Wu J, Zhang CY, et al. Application of the albumin-bilirubin grade for predicting prognosis after curative resection of patients with early-stage hepatocellular carcinoma. Clin Chim Acta. 2016 Nov; 462:15-22.

55 Andreatos N, Amini N, Gani F, Margonis GA, Sasaki K, Thompson VM, et al. Albumin-Bilirubin Score: Predicting Short-Term Outcomes Including Bile Leak and Post-hepatectomy Liver Failure Following Hepatic Resection. J Gastrointest Surg. 2017 Feb;21(2):238-48.

56 Zou H, Yang X, Li QL, Zhou QX, Xiong L, Wen Y. A Comparative Study of Albumin-Bilirubin Score with ChildPugh Score, Model for End-Stage Liver Disease Score and Indocyanine Green R15 in Predicting Posthepatectomy Liver Failure for Hepatocellular Carcinoma Patients. Dig Dis. 2018;36(3):236-43.

57 Zou H, Wen Y, Yuan K, Miao XY, Xiong L, Liu KJ. Combining albumin-bilirubin score with future liver remnant predicts post-hepatectomy liver failure in HBV-associated HCC patients. Liver Int. 2018 Mar;38(3):494-502.

58 Oh IS, Sinn DH, Kang TW, Lee MW, Kang W, Gwak GY, et al. Liver Function Assessment Using Albumin-Bilirubin Grade for Patients with Very Early-Stage Hepatocellular Carcinoma Treated with Radiofrequency Ablation. Dig Dis Sci. 2017 Nov;62(11):3235-42.

59 He W, Peng B, Tang Y, Yang J, Zheng Y, Qiu J, et al. Nomogram to Predict Survival of Patients with Recurrence of Hepatocellular Carcinoma after Surgery. Clin Gastroenterol Hepatol. 2018 May;16(5):756-64.

60 Kao WY, Su CW, Chiou YY, Chiu NC, Liu CA, Fang KC, et al. Hepatocellular Carcinoma: Nomograms Based on the Albumin-Bilirubin Grade to Assess the Outcomes of Radiofrequency Ablation. Radiology. 2017 Nov; 285(2):670-80.

61 Hickey R, Mouli S, Kulik L, Desai K, Thornburg B, Ganger D, et al. Independent Analysis of Albumin-Bilirubin Grade in a 765-Patient Cohort Treated with Transarterial Locoregional Therapy for Hepatocellular Carcinoma. J Vasc Interv Radiol. 2016 Jun;27(6):795-802.

62 Gui B, Weiner AA, Nosher J, Lu SE, Foltz GM, Hasan O, et al. Assessment of the Albumin-Bilirubin (ALBI) Grade as a Prognostic Indicator for Hepatocellular Carcinoma Patients Treated with Radioembolization. Am J Clin Oncol. 2018 Sep;41(9):861-6.

63 Waked I, Berhane S, Toyoda H, Chan SL, Stern N, Palmer D, et al. Transarterial chemo-embolisation of hepatocellular carcinoma: impact of liver function and vascular invasion. Br J Cancer. 2017 Feb;116(4):448-54. 
64 Ho SY, Liu PH, Hsu CY, Hsia CY, Lee YH, Lee RC, et al. Prognostic role of noninvasive liver reserve markers in patients with hepatocellular carcinoma undergoing transarterial chemoembolization. PLoS One. 2017 Jul; 12(7):e0180408.

65 Hiraoka A, Kumada T, Kudo M, Hirooka M, Koizumi Y, Hiasa Y, et al.; Real-life Practice Experts for HCC (RELPEC) Study Group and HCC 48 Group (hepatocellular carcinoma experts from 48 clinics). Hepatic Function during Repeated TACE Procedures and Prognosis after Introducing Sorafenib in Patients with Unresectable Hepatocellular Carcinoma: multicenter Analysis. Dig Dis. 2017;35(6):602-10.

66 Chong CC, Chan AW, Wong J, Chu CM, Chan SL, Lee KF, et al. Albumin-bilirubin grade predicts the outcomes of liver resection versus radiofrequency ablation for very early/early stage of hepatocellular carcinoma. Surgeon. 2018 Jun;16(3):163-70.

67 Chong CC, Lee KF, Chu CM, Chan AW, Wong J, Chan SL, et al. Microwave ablation provides better survival than liver resection for hepatocellular carcinoma in patients with borderline liver function: application of ALBI score to patient selection. HPB (Oxford). 2018 Jun;20(6):546-54.

68 Hiraoka A, Kumada T, Hirooka M, Tsuji K, Itobayashi E, Kariyama K, et al.; Real-life Practice Experts for HCC (RELPEC) Study Group and HCC 48 Group (hepatocellular carcinoma experts from 48 clinics). A better method for assessment of hepatic function in hepatocellular carcinoma patients treated with radiofrequency ablation: usefulness of albumin-bilirubin grade. Hepatol Res. 2018 Feb;48(3):E61-7.

69 Ogasawara S, Chiba T, Ooka Y, Suzuki E, Kanogawa N, Saito T, et al. Liver function assessment according to the Albumin-Bilirubin (ALBI) grade in sorafenib-treated patients with advanced hepatocellular carcinoma. Invest New Drugs. 2015 Dec;33(6):1257-62.

70 King J, Palmer DH, Johnson P, Ross P, Hubner RA, Sumpter K, et al. Sorafenib for the Treatment of Advanced Hepatocellular Cancer - a UK Audit. Clin Oncol (R Coll Radiol). 2017 Apr;29(4):256-62.

71 Takayasu K, Arii S, Ikai I, Omata M, Okita K, Ichida T, et al.; Liver Cancer Study Group of Japan. Prospective cohort study of transarterial chemoembolization for unresectable hepatocellular carcinoma in 8510 patients. Gastroenterology. 2006 Aug;131(2):461-9.

72 Kudo M. A New Era of Systemic Therapy for Hepatocellular Carcinoma with Regorafenib and Lenvatinib. Liver Cancer. 2017 Jun;6(3):177-84.

73 Kudo M, Matsui O, Izumi N, Kadoya M, Okusaka T, Miyayama S, et al.; Liver Cancer Study Group of Japan. Transarterial chemoembolization failure/refractoriness: JSH-LCSGJ criteria 2014 update. Oncology. 2014;87 Suppl 1:22-31.

74 Raoul JL, Gilabert M, Piana G. How to define transarterial chemoembolization failure or refractoriness: a European perspective. Liver Cancer. 2014 May;3(2):119-24.

75 Hiraoka A, Horiike N, Yamashita Y, Koizumi Y, Doi H, Yamamoto Y, et al. Risk factors for death in 224 cases of hepatocellular carcinoma after transcatheter arterial chemoembolization. Hepatogastroenterology. 2009 Jan-Feb;56(89):213-7.

76 Yamakado K, Miyayama S, Hirota S, Mizunuma K, Nakamura K, Inaba Y, et al. Subgrouping of intermediatestage (BCLC stage B) hepatocellular carcinoma based on tumor number and size and Child-Pugh grade correlated with prognosis after transarterial chemoembolization. Jpn J Radiol. 2014 May;32(5):260-5.

77 Hucke F, Sieghart W, Pinter M, Graziadei I, Vogel W, Müller C, et al. The ART-strategy: sequential assessment of the ART score predicts outcome of patients with hepatocellular carcinoma re-treated with TACE. J Hepatol. 2014 Jan;60(1):118-26.

78 Hiraoka A, Ishimaru Y, Kawasaki H, Aibiki T, Okudaira T, Toshimori A, et al. Tumor Markers AFP, AFP-L3, and DCP in Hepatocellular Carcinoma Refractory to Transcatheter Arterial Chemoembolization. Oncology. 2015; 89(3):167-74.

79 Arizumi T, Ueshima K, Iwanishi M, Minami T, Chishina H, Kono M, et al. The Overall Survival of Patients with Hepatocellular Carcinoma Correlates with the Newly Defined Time to Progression after Transarterial Chemoembolization. Liver Cancer. 2017 Jun;6(3):227-35.

80 Izumoto H, Hiraoka A, Ishimaru Y, Murakami T, Kitahata S, Ueki H, et al. Validation of Newly Proposed Time to Transarterial Chemoembolization Progression in Intermediate-Stage Hepatocellular Carcinoma Cases. Oncology. 2017;93 Suppl 1:120-6.

81 Hiraoka A, Michitaka K, Kumada T, Izumi N, Kadoya M, Kokudo N, et al. Prediction of prognosis of intermediate stage HCC patients - validation of tumor marker score in nationwide database in Japan. Dig Dis. (In press).

82 Edeline J, Blanc JF, Johnson P, Campillo-Gimenez B, Ross P, Ma YT, et al. A multicentre comparison between Child Pugh and Albumin-Bilirubin scores in patients treated with sorafenib for Hepatocellular Carcinoma. Liver Int. 2016 Dec;36(12):1821-8.

83 Kuo YH, Wang JH, Hung CH, Rau KM, Wu IP, Chen CH, et al. Albumin-Bilirubin grade predicts prognosis of HCC patients with sorafenib use. J Gastroenterol Hepatol. 2017 Dec;32(12):1975-81.

84 Pinato DJ, Yen C, Bettinger D, Ramaswami R, Arizumi T, Ward C, et al. The albumin-bilirubin grade improves hepatic reserve estimation post-sorafenib failure: implications for drug development. Aliment Pharmacol Ther. 2017 Mar;45(5):714-22.

85 Lee PC, Chen YT, Chao Y, Huo TI, Li CP, Su CW, et al. Validation of the albumin-bilirubin grade-based integrated model as a predictor for sorafenib-failed hepatocellular carcinoma. Liver Int. 2018 Feb;38(2):321-30.

86 Khabbaz RC, Lokken RP, Chen YF, Lipnik AJ, Bui JT, Ray CE Jr, et al. Albumin-Bilirubin and Platelet-AlbuminBilirubin Grades Do Not Predict Survival After Transjugular Intrahepatic Portosystemic Shunt Creation. Cardiovasc Intervent Radiol. 2018 Mar;41(7):1029-34. ; Epub ahead of print. 
87 Ronald J, Wang Q, Choi SS, Suhocki PV, Hall MD, Smith TP, et al. Albumin-bilirubin grade versus MELD score for predicting survival after transjugular intrahepatic portosystemic shunt (TIPS) creation. Diagn Interv Imaging. 2018 Mar;99(3):163-8.

88 Lo CH, Liu MY, Lee MS, Yang JF, Jen YM, Lin CS, et al. Comparison Between Child-Turcotte-Pugh and AlbuminBilirubin Scores in Assessing the Prognosis of Hepatocellular Carcinoma After Stereotactic Ablative Radiation Therapy. Int J Radiat Oncol Biol Phys. 2017 Sep;99(1):145-52.

89 Na SK, Yim SY, Suh SJ, Jung YK, Kim JH, Seo YS, et al. ALBI versus Child-Pugh grading systems for liver function in patients with hepatocellular carcinoma. J Surg Oncol. 2018 Apr;117(5):912-21. ; Epub ahead of print.

90 Dong ZR, Zou J, Sun D, Shi GM, Ke AW, Cai JB, et al. Preoperative Albumin-Bilirubin Score for Postoperative Solitary Hepatocellular Carcinoma within the Milan Criteria and Child-Pugh A Cirrhosis. J Cancer. 2017 Oct; 8(18):3862-7.

91 Omata M, Cheng AL, Kokudo N, Kudo M, Lee JM, Jia J, et al. Asia-Pacific clinical practice guidelines on the management of hepatocellular carcinoma: a 2017 update. Hepatol Int. 2017 Jul;11(4):317-70.

92 Yau T, Tang VY, Yao TJ, Fan ST, Lo CM, Poon RT. Development of Hong Kong Liver Cancer staging system with treatment stratification for patients with hepatocellular carcinoma. Gastroenterology 2014;146:1691-700. 